Iranian Journal of Applied Linguistics (IJAL), Vol.18, No.1, March 2015, 167-200

\title{
Effect of Multiple Intelligences-Based Reading Instruction on EFL Learners' Reading Comprehension and Critical Thinking Skills
}

\section{Ali Roohani *}

Assistant Professor of Applied Linguistics, Shahrekord University, Shahrekord, Iran

Azizullah Mirzaei

Associate Professor of Applied Linguistics, Shahrekord University, Shahrekord, Iran

\section{Marzieh Poorzangeneh}

M.A. in TEFL, Shahrekord University, Shahrekord, Iran

Received 5 January 2014; revised 16 December 2014; accepted 5 January 2015

\begin{abstract}
Reading comprehension (RC) and critical thinking (CT) are the two basic cognitive skills that should be developed through involving language learners in a carefully planned instruction. Multiple intelligences (MI) instruction may assist learners in developing RC and CT in L2 education. This study probed the effect of MI-based reading instruction on the Iranian EFL learners' RC and CT skills. In so doing, it compared the effectiveness of an MI-based reading instruction with a traditional one. To this end, 4 intact classes from several English language institutes, comprising 56 Iranian intermediate-level EFL learners, were selected and randomly assigned to MI-based (experimental) and traditional (control) groups. A multiple-

*E-mail address: roohani-a@lit.sku.ac.ir Corresponding address: English Department, Faculty of Literature \& Humanities, Shahrekord University, the $2^{\text {nd }}$ Kilometer of Saman Road, Shahrekord, Iran.
\end{abstract}


choice RC test, a reading summary test, and the Watson-Glaser Critical Thinking Appraisal test were used as the instrumentations to collect data on the participants' RC and CT. Analysis of covariance revealed a significant effect for the MI-based reading instruction. Furthermore, the RC scores increased more significantly in the MI-based group in comparison to the traditional one. However, the CT scores did not significantly improve in both groups. There was also no statistically significant difference in the CT scores between the two groups after the treatments. Iranian EFL educators are, then, encouraged to develop MI-based lessons and activities for diverse students and take explicit instruction for the enhancement of CT skills in EFL reading courses.

Keywords: EFL Reading comprehension; Multiple intelligences; MI-based reading instruction; Critical thinking

\section{Introduction}

Multiple intelligences (MI) theory, originally proposed by Gardner in the 1980s, challenged the classical notion of intelligence and changed the attitude toward a very limited conception of intelligence. Furthermore, having challenged the view of intelligence as a monolithic inborn factor which could be assessed merely through IQ tests, Gardner (1983) regarded intelligence as a pluralistic construct made up of several abilities. To Gardner (1999), intelligence is "a biopsychological potential for information processing that can be activated in a cultural setting to solve problems or [create] products that are of value in a culture" (p. 34). He identified different types of intelligences and regarded intelligence as a combination of the diverse but interdependent forms: linguistic, logicalmathematical, spatial, bodily-kinesthetic, musical, interpersonal, intrapersonal, and naturalist.

MI theory has been taken up and extended by many educationalists since the 1980s. MI can have several implications for education, in general (Armstrong, 2009; Hoerr, Boggeman, \& Wallach, 2010), and language pedagogy, in particular (Christison, 1996; Simpson, 2000; Tahriri \& Yamini, 2010). It can account for students' individual differences, specific interests, and needs, and it can help the 
teachers provide students with the pedagogical activities designed according to their developmental features (Armstrong, 2009). Furthermore, it can be used to identify learning dispositions of various language learners (Tahriri \& Yamini, 2010) and produce differential outcomes in language learning (Haley, 2004). MI theory with its view of learners' diversity in intelligence profiles can contribute to teachers' more accurate identification of student's cognitive skills for the purpose of better addressing their disabilities (Armstrong, 2009).

Reading comprehension (RC) and critical thinking (CT) are two cognitive skills which may allow for the application of MI instruction in second/foreign language (L2) learning. As Armstrong (2004) states, MI theory provides a framework through which several diverse faces of reading process can be viewed. In fact, RC involves an interactive process in which the reader actively constructs meaning through a set of complex cognitive processes (Li \& Kirby, 2014). Reading is an active intentional thinking process requiring higher-order cognitive skills (Kobayashi, 2007; Neufeld, 2005). That is to say, RC is directly or indirectly linked with various higher-thinking features (Barnet \& Bedau, 2010). As Mohd Zin, Bee Eng, and Rafik-Galea (2014) clearly state, thinking critically, making inferences, reasoning, and judging are the cognitive processes which are involved in RC. Unfortunately, in traditional reading classes, readers are often viewed as passive decoders of different language components. However, as Waters (2006) points out, recent studies about RC have highlighted the role of higher-order cognitive processes and problem-solving techniques that make the language learners recognize, illuminate, assess, and solve bewilderments that arise in reading process. In other words, reading courses can prepare the ground for stimulating and applying CT, which itself makes use of cognitive processes such as interpretation, analysis, evaluation, and inference (Facione, 2011).

Nowadays, many scholars and educationalists (e.g., Moon, 2008; Paul \& Elder, 2006) consider CT as an essential skill not only for teachers but also for students. This is partly due to the contribution of high-order thinking skills to students' academic success. Moreover, to solve the problems that readers usually experience in traditional reading courses, the related research should consider alternatives to 
more traditional methods in teaching $\mathrm{L} 2$ reading. This study was then designed to implement $\mathrm{MI}$ instruction in an $\mathrm{L} 2$ reading course as a possible way to enhance $\mathrm{L} 2$ readers' cognitive skills of RC and CT. This issue becomes more important when MI literature has documented that MI components can contribute to the quality of students' learning and the development of their higher-order thinking skill in educational domains.

\section{Review of the Related Literature}

In 1904, Spearman suggested that mental performance could be conceptualized in terms of a single general ability factor, which he labeled " $g$ factor". He believed that the $\mathrm{g}$ factor existed independently of schooling and culture (Armstrong, 2009), and proposed a one-dimensional view toward intelligence, regarding it as a unitary inherited trait. In 1980s, the general intelligence theory was challenged by Howard Gardner and MI theory was put forward (Gardner, 1983). Gardner proposed that human brain was composed of different separate modules, or better to say, intelligences which would work independently. Gardner (1999) assumed eight distinct intelligences:

- Linguistic/verbal: It refers to the ability to reflect on the use of language in everyday life.

- Logical/mathematical: It demonstrates the expertise in calculation, reasoning, quantification, complex mathematical/logical operation, inference, and hypothesis testing.

- Spatial/visual: It includes the capacity for accurate perceptions of visual world.

- Bodily/kinesthetic: It encompasses the ability to skillfully use one's body for the expression of ideas and feelings.

- Musical: It refers to the expertise in understanding sounds, rhythms, melodies, and rhymes.

- Intrapersonal: It includes the knowledge and understanding that an individual may have about his/her own self. 
- Interpersonal: It includes the knowledge and understanding which an individual may possess of other people.

- Naturalist: It encompasses the recognition and classification of individuals, species, and ecological relationships.

Appreciating the learners' diversity and underscoring their uniqueness, MI theory has made it easier to discern the relationship between intelligence and language and it has become the specific focus of much research in L2 learning/teaching so far. For instance, Chen (2005) conducted a study to see if MI along with Cooperative Learning (CL) and Whole Language Approach (WLA) would have any effect on Taiwanese students' English proficiency. The results of his study indicated that implementation of MI and CL in EFL classes failed to lead to a significant increase in the students' language proficiency. However, Haley's (2001) investigation into the application of MI in several foreign language classrooms revealed a positive impact of MI on both foreign language teachers and students' attitude. In Haley's study, the students were divided into experimental and control groups. The students in the experimental groups were taught through MI instruction, while the students in the control group were taught using traditional instruction. The results of her study revealed that the teachers in the experimental groups were more energized. The students had also more interest in MI and expressed positive attitudes towards foreign language learning. Furthermore, Akbari and Hosseini (2007) explored the relationship between the use of L2 learning strategies and learners' MI scores and found that MI could correspond to certain aspects of language use such as communication skills.

A few studies were conducted to explore the role of MI in relation to reading ability. For instance, McMahon, Rose, and Parks (2004) in a study, which was designed to evaluate the reliability of the Teele Inventory of Multiple Intelligences (TIMI) and the relationship between intellectual preferences and reading achievement, found out that the urban fourth-grade students in Illinois with higher scores in logical-mathematical intelligence were more likely to demonstrate at or above grade-level RC scores compared with those students who scored lower on 
logical-mathematical intelligence, but none of the other MI scales were predictive of student achievement. In contrast, Al-Balhan's (2006) research, which assessed the effectiveness of MI styles in predicting middle-school Kuwaiti students' improved reading skills, revealed that those students whose MI was applied to learning performed better than those who studied using traditional teaching methodology. Al-Balhan's study further demonstrated that knowledge of a student's type of intelligence and appropriate teaching methods could improve the overall reading performance. Likewise, Sukeemok's (2012) research on the effect of using MI activities on Thai students' RC and their interest in learning English showed that MI-based instruction increased both the students' gains in RC and their interest in learning English. Moreover, the research conducted by Çelik (2012) showed that adjusting EFL learners' curriculum according to their intelligences bring many benefits in both improving their reading skill and developing awareness of their weaknesses and strengths in EFL classes.

Furthermore, the relationship of CT with MI and language skills was the subject of several investigations. For instance, Foong, Shariffudin, and Milsan (2012) reported a significant relationship between MI, personality traits, and CT skills. Besides, Hawkins's (2012) research on 119 college undergraduate students in the US supported the positive relationship between CT and voluntary reading. Also, while investigating the relationship between CT disposition and critical reading among Malaysian L2 learners, Mohd Zin and Bee Eng (2014) found out that lack of CT dispositional attitudes were reflected in L2 learners' poor reading performance. Consequently, they called for fostering CT and reading dispositions among Malaysian L2 students at secondary and tertiary levels. Being interested in improving CT among Chinese EFL students, Yumin and Henderson (2014) integrated $\mathrm{CT}$ into academic reading through virtual learning instruments and developed structured teaching and learning activities in English reading courses. The results of their study generated support for using reading skill to foster CT.

In sum, based on the related literature, there is some empirical evidence indicating a relationship between $\mathrm{CT}$ and reading strategies. There is also evidence for the relevance of $\mathrm{CT}$ to $\mathrm{L} 2 \mathrm{RC}$. Moreover, research partially demonstrates a 
positive relationship between MI and L2 RC. Nonetheless, not much research was conducted to explore the effect of an MI-based reading course on language learners' RC and CT in an EFL context. Previous research (e.g., Al-Balhan, 2010; Farjami 2002; Haley, 2004) has focused on the effectiveness of MI activities among children with low academic achievement or the effect of MI instruction in relation to general English proficiency. Given that the field of reading often deals with the controversies about the best way of its instruction, the results of the present study can make contribution to the ongoing debate about how to teach L2 reading effectively. Additionally, the related literature has emphasized CT as a basic skill for higher education (Ennis, 2003; Moon, 2008). However, the ways in which CT can be fostered, sustained, and evaluated in reading courses are not sufficiently explored (Mehta \& Al-Mahrooqi, 2014). Apparently, MI comprises components which may be potentially helpful for a person to be a critical thinker. Given that reading can provide the ground for applying CT, comparing the effect of an MI-based reading instruction with a traditional one i.e., the instruction which focuses on traditional view of intelligence in a teacher-centered class, seems to be valuable to EFL teachers and fills in the gap in the related literature. In this light, the following research questions were addressed in the present study:

1. Is an MI-based reading instruction significantly more effective than a traditional one in improving the Iranian EFL learners' RC?

2. Is an MI-based reading instruction significantly more effective than a traditional one in improving the Iranian EFL learners' CT?

\section{Method}

\section{Participants}

The participants of the study included 56 (19 male and 37 female) Iranian intermediate EFL learners from three private English language institutes in Isfahan. They were native speakers of Persian and their ages varied from 19 to 22 . The participants constituted four classes, each with 14 EFL students. They were randomly assigned to experimental $(n=28)$ and control $(n=28)$ groups, taught by the same instructor. The present study had a quasi-experimental design in which 
complete randomization was not possible. The participants of the study were in intermediate-level courses and were studying Four Corners, book 3 (Richards \& Bohlke, 2012), containing 6 reading passages, and four units of Active Skills for Reading, book 3 (Anderson, 2007) as the supplementary material.

\section{Instruments}

This study used three instruments for data collection: a RC test, a reading summary test, and the Watson-Glaser Critical Thinking Appraisal (WGCTA) test. The RC test, developed by the present researchers included four passages with 39 (23 multiple-choice and 16 true/false) items. Care was exercised to develop items which mostly demanded inference, prediction, and critical reading, with few display questions (see Appendix A). The test included the sub-skill of inference, reference, main idea, and specific information (stated details). Moreover, the readability indices of the passages, calculated through Flesch-Kincaid readability test, displayed the Flesch Reading Ease scores ranging from 68.2 to 68.8 with Flesch-Kincaid Grade Level of 6.7 to 7.4 (which were neither very easy nor very difficult for the intermediate-level participants). Meanwhile, the score for the 39item reading test could range from 0 to 39 .

To validate the reading test, this study used evidence from content validity and structural equation modeling (SEM). Item specifications (including instruction specifications, item types, length of texts, and difficulty/reading level) were prepared to guide the test developers i.e., present researchers, to better elicit aspects of content domain and exclude construct-irrelevant content. The content validity of the test was determined through experts' judgments and pilot-testing to ensure that the test was carefully and accurately planned to include the required reading items. Moreover, Analysis of Moment Structures (AMOS) was used for factor analysis on the data obtained form 100 EFL learners. AMOS software builds models more accurately than those with standard multivariate statistics techniques (Arbuckle, 2007). AMOS specifies, estimates, assesses, and presents models in an intuitive path diagram to show the hypothesized relationships among variables by drawing on SEM. As Schreiber, Stage, King, Nora, and Barlow (2006) state, SEM is a statistical technique which can be utilized to diminish the number of observed 
variables into a smaller number of latent variables by exploring the co-variation among the observed variables. It extends the possibility of relationships among the latent variables and consists of two components: (a) a measurement model, and (b) a structural model. In fact, SEM is a means for researchers "to test theoretical propositions regarding how constructs are theoretically linked and directionality of significant relationships" (Schreiber et al., 2006, p. 325). Regarding the present reading test, one path diagram was presented for each reading passage to see how well it fitted the observed data (i.e., the reading questions related to each passage). As to the reliability of the RC test, the Cronbach's alpha statistic was acceptable (0.84).

To further assess the reading ability of the participants, a reading summary test was also utilized. Through this assessment tool, a reader should be able to reduce a text to its main points. This ability involves recognizing and eliminating unnecessary information. It is an effective method to assess reading and one of the most frequently used activities after reading a text (Cho, 2012; Kissner, 2006). As Kirkland and Saunders (1991) state, the reading summary test requires the ability to process information repeatedly by working back and forth between the texts and use selecting, planning, integrating, and monitoring. According to Kintsch and van Dijk, this method is very effective since "readers, when comprehending a passage, form a gist that represents their overall comprehension of the passage" (cited in Kim, 2001, p. 571). With respect to the gist, it represents what readers have understood about the text and is regarded as a valid measure of RC (Yu, 2008). According to Rinehart, Stahl, and Ericson (1984), it involves complex cognitive processes requiring the ability to interact with the text. Thus, summarizing training was specially designed to help the participants develop text comprehension and bring their ideas to their reading through interacting with the text. In the current study, the participants were asked to summarize two texts (comprised of 344-364 words with the average Flesch Reading Ease scores of 65.5) to check and review how well they understood what they were asked to read (see Appendix B). Each participant's summary test was scored by using Hoyt's (2010) Summarization Scoring Rubric. The participants were asked to summarize the text in 10 sentences 
following what they had read (see Appendix B). They were scored " 2 " if they completely supported the idea in the reading text, they received " 1 " if they mentioned the idea in the text, but not fully supported the idea, and " 0 " if the idea was not present in summary. This way, every participant's summary was scored on an interval scale ranging from 0 to 20 by two raters; the average scores of the two raters constituted each participant's reading summary score. Meanwhile, the interrater reliability coefficients of the reading summary tests, administered as the pretest and posttest, were 0.87 and 0.90 respectively. In summary, the aggregate of interval-scale scores from the aforementioned validated RC and summary instruments made up the participants' scores (ranging from 0-59) for assessing reading ability in the present study.

To assess the participants' CT ability, the WGCTA test (Watson \& Glaser, 1980) was employed. This test includes 80 items and five subscales of inference, recognition of the assumption, deduction, interpretation, and evaluation of argument. According to Watson and Glaser (1980), the test-retest reliability of the WGCTA test is high and this test possesses face, content, criterion, and construct validity. The WGTCA test was designed for English native speakers. To avoid any misunderstanding, the translated version of this test was used in this study. The translated version was validated in the context of Iran by Mohammadyari (2002). Moreover, Ghanizadeh and Moafian (2011) state that the results of the factor analysis of the translated version presented support for the inventory hypothesis structure. In the present study, the reliability of the test, calculated through Cronbach's alpha, was 0.71 .

\section{Procedure}

At the outset of the study, a reading test was developed by the researchers to assess the EFL participants' RC ability. The test was initially composed of four passages, 27 multiple-choice, and 27 true/false items. After the readability indices of the passages were checked, the test was given to two experts to evaluate the items and the passages in terms of content and level appropriacy for Iranian intermediatelevel EFL learners. The test was piloted on $30 \mathrm{EFL}$ students to determine the desirability of the instruction, length of the passages, the level of difficulty, and the 
time for completing it. Then, the revised RC test was given to 100 intermediatelevel EFL learners to collect data for establishing its construct validity through AMOS (version 8). To examine the convergent and discriminant validity of the test, CFA (confirmatory factor analysis) was applied and the parameters were estimated using the MLE (the maximum likelihood estimation) technique. The regression weights were computed for each of the items in the four passages. Based on the critical ratio (the estimate divided by the standard error), 15 items ( 6 items from passage 1, 4 items from passage 2, 2 items from passage 3, and 3 items from passage 4) were excluded from further analysis due to low factor loading values. The goodness of fit was assessed through the goodness of fit indicators (RMSEA, Chi-square, probability level of the related model, comparative fit index (CFI), non-normalized fit index (NNFI), and the standardized root mean square residual. RMSEA i.e., the corrected statistic that gives a penalty for model complexity, was small. Besides, the non-significant Chi-square indices indicated no significant discrepancy between the model and the data (See Table B1 in Appendix C). Thus, the test with four passages and 39 items had construct validity.

This research had a pretest-posttest control group design. Four intact EFL classes from the above-mentioned language institutes, comprising 56 Iranian intermediatelevel EFL learners, were selected and randomly assigned to the MI-based and the traditional groups. Two MI-based classes were considered as the experimental group $(n=28)$ and two traditional classes were considered as the control group of this study $(n=28)$. At the beginning of the course, the summarization training was provided to make the participants of both groups more aware of the structure of ideas within the text and how individual ideas relate to each other. Then, the Persian version of the WGCTA test, the validated RC, and the reading summary test were administered as the pretests in both experimental and control groups.

After the pretests, the treatments were given to both groups for 20 sessions, about 1 hour per session by the same instructor (an M.A student and teacher researcher who was a skilled part-time teacher in the language institutes). In the experimental group, the teacher's role was to consider the students' diverse strengths and differences though providing different activities to support individual 
intelligences. Inspired with Armstrong's (2009) book, Multiple Intelligence in the classroom, the teacher researcher, who had adequate knowledge of MI instruction, set up activities to demonstrate functioning within a particular intelligence.

In the experimental group, before reading the texts, the teacher used various pictures and illustrations related to the themes/topics of the reading texts. She encouraged the participants to think before starting to talk in the classroom. She sought to engage her students mentally and attract their attention to the content of the reading materials by connecting visual information/cues to their personal life experiences. Then, they were invited to share their knowledge and experiences in pairs. Sometimes they were asked to brainstorm a list of important events and experiences in their lives with regard to the content of the illustrations presented to them. Afterwards, they were asked to have one-minute reflection period to think about what they were going to read and make predictions on the content of their reading. Meanwhile, reading readiness (prior to actual reading) was achieved through questioning or writing several key terms on the board. Before a close reading, the participants in the experimental group were required to scan the text, find new vocabularies, and highlight them with colored markers. Then, Popcorn reading was used; that is, one student read some parts of the text and called on another student to continue reading. Therefore, the whole class could be involved in reading the text aloud. All of the students were advised to track their reading with a bookmark or finger. Moreover, the participants were requested to read their assigned text in pairs, and discuss the events, raise questions about what they had read, and make a gloss of new vocabularies (if necessary). Whenever it was possible, background music was played during the reading period. Also, the teacher asked the participants to help her make attribute webs on the board about what they had read and, if possible, to dramatize or retell the story in their own words. If their reading passage was related to the natural phenomena, patterns in nature (e.g. climate or seasons), and natural habitats (e.g., forests, or deserts), the participants were requested to imagine the scene and describe it. Further, they were encouraged to keep a journal to list information about such characteristics as size, color, form, function, or habitat. In the follow up, they were asked to share two or 
more things they had learned from the text; they answered the follow-up questions in groups. At times, they were invited to make analogies between the content of the text and the experiences in their own lives, or make a Venn diagram (diagram of similarities and differences between characters in the text). Moreover, they were invited to debate decisions made by a character in the text and write their thoughts and emotions about the character or events in their journals. Additionally, they were requested to create flashcards for new words they came across in reading materials.

In the control group, the EFL participants studied the same reading texts, but the teacher used the traditional reading instruction i.e., the teacher-centered instruction which would be applied in most reading classrooms in Iran. Here, the teacher mostly retained the right to ask questions and evaluate them. The traditional class focused on rote learning and memorization; the students' interests, differences, and strengths were less taken into account by the teacher. Besides, verbal/linguistic abilities (conceptualized in the traditional view of intelligence) were mostly the focus of instruction.

In the control group, the teacher asked the participants to read the assigned texts before attending the classroom. They were required to find the meaning of new vocabularies in their dictionaries before attending the class and memorize them. Then, the teacher selected one of the students in the classroom to read a paragraph from the text aloud. The teacher herself read the paragraph aloud again and paraphrased it sentence by sentence. She seldom asked the EFL participants about the meaning of difficult words. The students were not allowed to work in pairs and discuss their questions in groups; rather, they were encouraged to be silent in the classroom. In the end, a few students were called on to read aloud their answers to follow-up written questions. In general, the combination of intelligences was not the focus of instruction in the control group and the teacher had control over the presentation of reading materials. The students' job was mainly to provide the right answer to the instructor's questions; hence, they had a more passive role in the traditional classroom. 
After carrying out the treatments for more than a month, the WGCTA and RC tests, together with another reading summary test, were administered to the participants in both groups as the posttests. Meanwhile, given pretest-posttest design of study, analysis of covariance (ANCOVA) was used as a statistical tool for data analysis. According to Larson-Hall (2010), "such a technique may be useful when you assume that there is some external factor, such as pre-test ... which will affect how your students will perform on the response variable" (p. 357). ANCOVA is like repeated-measures, but it can "reduce the amount of variability in the model that is unexplained" (Larson-Hall, 2010, p. 357), and factor out the effects of possible pre-existing differences in reading ability.

\section{Results}

The descriptive statistics for the RC and CT scores in both control and experimental groups of this study are presented in Table 1. As Table 1 shows, the pretest RC mean scores in the experimental $(M=33.89)$ and control $(M=33.64)$ were lower than the posttest RC mean scores in the experimental $(M=43.10)$ and control $(M=40.00)$ groups. This result suggests that the participants in both groups performed better on RC at the posttest phase. However, compared with the RC mean scores, the mean differences between the pretest and posttest CT scores were not great in both control $(M=45.61$ and $M=46.57)$ and experimental $(M=45.75$ and $M=45.50)$ groups.

\section{Table 1}

Descriptive Statistics of the RC and CT Scores in Experimental and Control

Groups

\begin{tabular}{lllll}
\hline Group & Variable & N & M & SD \\
\hline Pretest RC & 28 & 33.89 & 3.08
\end{tabular}

Experimental

Posttest RC

$\begin{array}{lll}28 & 43.10 & 3.39\end{array}$




\begin{tabular}{|c|c|c|c|c|}
\hline & Pretest CT & 28 & 45.61 & 5.45 \\
\hline & Posttest CT & 28 & 46.57 & 5.17 \\
\hline \multirow{4}{*}{ Control } & Pretest RC & 28 & 33.64 & 2.83 \\
\hline & Posttest RC & 28 & 40.00 & 4.05 \\
\hline & Pretest $\mathrm{CT}$ & 28 & 45.75 & 6.13 \\
\hline & Posttest CT & 28 & 45.50 & 5.56 \\
\hline
\end{tabular}

In order to find out whether MI-based reading instruction significantly improved the EFL learners' RC and CT skills respectively, two paired $t$ tests were run on the pretest and posttest $\mathrm{RC}$ and $\mathrm{CT}$ scores after checking the normality of distribution and equal variance of RC and CT scores in both groups of study (See Appendix C, Tables $\mathrm{C} 1$ and $\mathrm{C} 2$ ). The Kolmogrov-Smirnov values in both experimental $(.159, p=.068)$ and control $(.161, p=.060)$ groups were more than .05. In addition, the Levene's test statistics in both experimental $(F=.687, p=$ $.411)$ and control $(F=.071, p=.791)$ groups were larger than the level of significance. Therefore, both groups were homogeneous in terms of RC and CT scores and there was not a statistically significant difference in the variances between the two groups, all indicating that the groups were homogenous before conducting the treatments. 
The results of the two $t$ tests are summarized in Table 2. The results on the reading scores revealed a significant increase in the scores from the pretest $(M=$ $33.89, S D=3.08)$ to the posttest $(M=43.10, S D=3.39), t(27)=20.24 * p \leq .05$. That is to say, the mean increase (9.21) was statistically significant. In contrast, the results of $t$ test on the CT scores, as demonstrated in Table 2, revealed no significant difference from the pretest $(M=45.61, S D=5.45)$ to the posttest $(M=$ $46.57, S D=5.17)$ in the experimental group, $t(27)=1.75$; the mean difference (.96) was not statistically significant.

Table 2

Paired t Test on the Pretest and Posttest RC and CT Scores

\begin{tabular}{|c|c|c|c|c|c|c|c|c|}
\hline & \multicolumn{5}{|c|}{ Paired Differences } & \multirow{3}{*}{$t$} & \multirow{3}{*}{$d f$} & \multirow{3}{*}{ Sig. ${ }^{a}$} \\
\hline & \multirow[t]{2}{*}{ M } & \multirow[t]{2}{*}{ SD } & \multirow{2}{*}{$\begin{array}{l}\text { Std. } \\
\text { Error } \\
\text { Mean }\end{array}$} & \multicolumn{2}{|c|}{$\begin{array}{c}95 \% \text { Confidence } \\
\text { Interval }\end{array}$} & & & \\
\hline & & & & Lower & Upper & & & \\
\hline $\mathrm{RC}$ & 9.21 & 2.41 & .45 & 10.15 & 8.28 & 20.24 & 27 & .000 \\
\hline $\mathrm{CT}$ & .96 & 2.91 & .55 & 2.09 & .16 & 1.75 & 27 & .091 \\
\hline
\end{tabular}

${ }^{\mathrm{a}}$ two-tail at .05

To find out whether an MI-based reading instruction was more effective than a traditional one in improving the learners' $\mathrm{RC}$, a one-way ANCOVA was carried out. In order to conduct the ANCOVA procedure, a number of assumptions were checked (See Appendix C, Tables C1, C2, and C3). Results revealed that there was no interaction between the treatment and participants' pretest RC scores, $F(1,53)$ $=.82, p=.370$ (See Appendix C, Table C3). That is to say, there was not a very significant difference between the groups in terms of RC prior to carrying out the treatments.

The first research question focused on the comparative effectiveness of the treatments in the experimental and control groups. The results of ANCOVA, as 
presented in Table 3, showed that there was a statistically significant difference between the two groups of the study in terms of RC scores on the posttest, $F(1,53)$ $=16.60,{ }^{*} p<.05$. The results of post hoc comparison test manifested a significant mean difference between the adjusted reading mean scores in the control $(M=$ 40.11) and experimental $(M=42.96)$ groups. In other words, the treatment i.e., the MI-based reading instruction, in the experimental group was more effective. However, the partial eta squared, indicating the effect size of the treatment, was medium (0.24), meaning that only $25 \%$ of variance in the posttest RC scores was due to the treatment.

Table 3

Analysis of Covariance for the Treatment Effect on Posttest Reading Scores

\begin{tabular}{lcccccc}
\hline Source & Sum of Squares & $d f$ & Mean Square & $F$ & Sig. & $\begin{array}{c}\text { Partial Eta } \\
\text { Squared }\end{array}$ \\
\hline Corrected Model & 519.32 & 2 & 259.66 & 37.14 & .000 & .584 \\
Intercept & 50.97 & 1 & 50.97 & 7.29 & .009 & .121 \\
Pre-test & 384.16 & 1 & 384.16 & 54.95 & .000 & .509 \\
Group(Treatment) & 116.06 & 1 & 116.06 & 16.60 & .000 & .239 \\
Error & 370.52 & 53 & 6.99 & & & \\
Total & 97585. & 56 & & & & \\
\hline
\end{tabular}

Table 4

Post Hoc Comparison Test on Adjusted Posttest Reading Mean Scores

\begin{tabular}{|c|c|c|c|c|c|c|}
\hline \multirow[t]{2}{*}{ Group } & & \multirow[t]{2}{*}{ Mean Difference } & \multirow{2}{*}{$\begin{array}{l}\text { Std. } \\
\text { Error }\end{array}$} & \multirow[t]{2}{*}{ Sig. } & \multicolumn{2}{|c|}{ 95\% Confidence Interval for Difference } \\
\hline & & & & & Lower Bound & Upper Bound \\
\hline Con. & Exp. & 2.88 & .707 & .000 & 4.30 & 1.46 \\
\hline
\end{tabular}

Con. $=$ Control; Exp. $=$ Experimental

The second research question of the study was intended to investigate whether MI-based reading instruction was significantly more effective than a traditional one in improving Iranian EFL learners' CT level. To examine this question, another 
ANCOVA was carried out after checking the homogeneity of the groups in terms of CT scores, equality of variance across both groups (See Appendix C, Tables C1 and $\mathrm{C} 2$ ), the reliability of the covariate i.e., the pretest CT scores (See Instrument section), and non-significant interaction effect between the covariate and the treatment, $F(1, .52)=.000, p=.983$ (See Appendix C, Table C4).

As displayed in Table 5, the results of one-way ANCOVA revealed a strong linear relationship between the pretest and posttest CT scores; the $p$ value of the pretest CT scores was found to be significant, $F(1,53)=165.78 * p<.05$. However, the group variable, i.e. the type of instruction, was not statistically significant, $F(1,57)=2.78, p=.102$. As depicted in Table 6 , the adjusted mean difference of CT between the control $(M=45.44)$ and experimental $(M=46.62)$ groups in the posttests was very small (1.18) and not statistically significant. This means that the type of treatment did not have a significant impact on the EFL participants' posttest CT scores $(p>.05)$.

Table 5

Analysis of Covariance for the Treatment Effect on Posttest CT Scores

\begin{tabular}{lcccccc}
\hline \multicolumn{1}{c}{ Source } & $\begin{array}{c}\text { Sum of } \\
\text { Squares }\end{array}$ & $d f$ & Mean Square & $F$ & Sig. & $\begin{array}{c}\text { Partial Eta } \\
\text { Squared }\end{array}$ \\
\hline Corrected Model & 1195.02 & 2 & 597.51 & 84.02 & .000 & .760 \\
Intercept & 73.82 & 1 & 73.82 & 10.38 & .002 & .164 \\
Pre-test CT & 1178.95 & 1 & 1178.97 & 165.78 & .000 & .758 \\
Group & 19.70 & 1 & 19.703 & 2.77 & .102 & .050 \\
(Treatment) & & & & & & \\
Error & 376.91 & 53 & 7.112 & & & \\
Total & 120252 & 56 & & & & \\
\hline
\end{tabular}


Table 6

Comparison Test on Adjusted Posttest CT Mean Scores

\begin{tabular}{cccccc}
\hline \multirow{2}{*}{ Group } & $\begin{array}{c}\text { Mean } \\
\text { Difference }\end{array}$ & Std. Error & Sig. & \multicolumn{2}{c}{$\begin{array}{c}\text { 95\% Confidence Interval for } \\
\text { Difference }\end{array}$} \\
\cline { 3 - 6 } & & & & Lower Bound & Upper Bound \\
\hline Con. Exp. & 1.186 & .713 & .102 & 2.616 & .243 \\
\hline
\end{tabular}

\section{Discussion}

The above-mentioned results showed that the MI-based instruction helped the EFL learners improve their reading skill effectively. It can be argued that this improvement may be due to the fact that diverse intelligences are accommodated in an MI-based reading instruction. As a case in point, as Armstrong (2003) states, the reading process initiates in the brain by receiving data about visual forms of the letters through eyes. As a consequence, operating visual-spatial activities can serve readers, especially those with high spatial-visual intelligence. Admittedly, the EFL participants accomplished something more than purely linguistically encoded data during reading, and their various intelligences were engaged in the reading process. As Armstrong (2003, p. 17) argues, during the reading process, different kinds of information such as "visual-spatial configurations, musical and oral sounds, and even physical sensations" are brought together to construct linguistic information. Through viewing the visual configuration of the letter, spatial intelligence can be engaged; the reader might envisage the text (i.e., spatial intelligence). Besides, for the accurate letter-sound correspondences in reading, the reader's knowledge of musical sounds is called upon (i.e., musical intelligence); the sounds of words are brought to the words in the texts (i.e., linguistic intelligence); and the reader might experience the text, live through it, feel engagement in it (i.e., bodily-kinesthetic), have emotional reactions to it (i.e., intrapersonal intelligence), make an attempt to have or reject the attitudes of the characters or authors (i.e., interpersonal intelligence), and think critically about the content of the text (i.e., logicalmathematical intelligence). 
Therefore, it is so likely that the MI activities employed in the present study accommodated a variety of individual intelligences in the experimental group and boosted the participants' RC. Using pictures associated with the reading texts, guessing the topics, predicting the content through visual images, highlighting the unknown vocabularies with colored markers, creating visual flashcards (visualspatial intelligence), having one-minute reflection period to think about what they had read, making Venn diagram, writing their thoughts on the events in the texts (intrapersonal intelligence), playing a piece of background music to create an appropriate mood (musical intelligence), tracking their reading with their finger or a bookmark (bodily-kinesthetic intelligence), making attribute webs on the board about what they read, making analogies, debating the decisions about some of the characters (logical intelligence), working in groups, sharing their attitudes and things they have learned from the texts (interpersonal intelligence), and Popcorn reading (linguistic and spatial intelligence) all contributed to better reading comprehension of the texts. However, the focus in the traditional instruction was basically on linguistic information and organizing the received information into grammatical units. In this light, the reader brought into play the syntactic structures which drew on logical-mathematical transformations. In addition, in the traditional instruction, the emphasis was on silent reading, not engaging the EFL learners who could excel at other types of intelligences such as musical and interpersonal intelligences. In contrast, the MI-based reading instruction made the EFL learners more engaged by involving visualization (pictures and drawings), music, reflective thinking, and interaction in reading process, which contributed to the effectiveness of the MI-based reading instruction.

The findings of this study supported the claim made by several scholars (e.g., Armstrong, 2003; Gaines \& Lehman, 2002) about the positive effect of MI practice on reading skill. In addition, the above results provided further empirical support for the findings of the previous studies by Al-Balhan (2006), Çelik (2012) and Sukeemok (2012), who reached the conclusion that language the learners' reading could be enhanced by MI style-tutoring programs.

As to the second research question, the results of the present study revealed that the MI-based reading instruction could enhance the EFL learners' CT, but the 
enhancement was not statistically significant. There may be several reasons for the low improvement of the participants' CT. To begin with, CT enhancement is not a rapid fire (Gelder, 2007). It takes a long time for a language learner to develop CT skills. According to Paul and Elder (2006), to be a well-cultivated thinker, an individual should pass through several stages, from unreflective thinker (who is unconscious of important problems in his or her own thinking) to the challenged thinker (who is conscious of problems in his or her own thinking), the beginning thinker (who tries to progress, but without consistent practice), the practicing thinker (who sees the necessity of consistent rehearsal), the advanced thinker (who progresses in line with his or her own practice), and the master thinker (who has astute thinking). Moreover, as Gelder (2005) asserts, CT requires a transfer of acquired knowledge, skill, and practice. Therefore, an individual should constantly evaluate and correct his or her own thinking. In the present study, the EFL participants of the study did not ask their peers many questions as expected and they were less engaged in thinking with their peers in the post-reading stage. Perhaps, if more time had been allocated to the MI-based reading instruction, and there had been much more focus on the challenging questions in the post-reading stage, there would have been more CT enhancement. Furthermore, CT requires students' reflection, discussion, and evaluation of information for solving problems (Mehta \& Al-Mahrooqi, 2014). Their fulfillment demands more direct instruction and a context where the students can use their knowledge and CT skills in the real world. However, in the context of classroom interaction, some of the EFL participants in the MI-based group were reserved and did not feel the urge to set forth new ideas, join group discussions, and express their attitudes, perhaps because they thought that they might be ridiculed in the classroom. In sum, the MIbased reading instruction could have a greater impact on the EFL learners' CT enhancement if they were engaged more with the information given to them, challenged it, and considered other students' attitudes.

\section{Conclusion}

The results of the present study revealed that the Iranian EFL learners benefited from an MI-based reading instruction and enhanced their RC. Unlike the traditional 
method of teaching reading, which was teacher-centered and mainly focused on silent reading and the learners' verbal/linguistic and logical abilities, the MI-based reading instruction dealt with a wide range of intelligences and resulted in the learners' greater reading achievement in English. The findings also indicated that the MI-based reading instruction did not significantly improve the CT skill in the EFL learners. The little improvement may be due to a number of reasons such as insufficient time specified for the treatment, indirect instruction to teach CT skill, less appropriate MI activities used for CT enhancement, or ineffectiveness of an MI-based reading instruction for improving CT skill.

The results of the current study imply that an MI-based instruction, unlike the traditional one, can benefit students with diverse MI styles in L2 reading courses. Implementation of such MI instructions can enhance L2 learners' reading skill. Thus, L2 teachers, textbook writers, and materials developers need to design suitable MI lessons and activities that engage students' various intelligences and involve both mind and body to improve their RC more effectively. In other words, reading skill should be nourished, to use Armstrong's (2003, p. 136) terms, with "music, art, nature experiences, logical analyses, dramatic performances, oral recitations, emotional expression, social interaction, and a wide range of other creative nutrients". Nonetheless, the findings of the current study do not support the strong claim that an MI-based reading instruction in L2 classes necessarily results in great enhancement of L2 learners' CT. Despite the widespread belief that being intelligent approximately equals being an excellent thinker, as De Bono (1995) states, some highly intelligent people are bad thinkers. Unlike intelligence, thinking is a skill which needs much time and practice (Jain, 2001). The results of the present study imply that L2 instructors should use more explicit instruction in $\mathrm{CT}$ enhancement. They also need to supplement MI activities with other techniques in long-term programs since an MI-based instruction in short-term programs by itself may not have the required features to greatly improve CT ability.

\section{Note on Contributors:}

Ali Roohani is a $\mathrm{PhD}$ holder in TEFL. He is currently a faculty member at Shahrekord University. His area of interest in L2 research includes emotional 
intelligence, multiple intelligences, and critical pedagogy. Recently, he has taken interest in textbook evaluation and materials development. He has published 43 papers and presented a number of papers in the national and international conferences.

Azizullah Mirzaei has numerous publications in different journals (e.g., JTLS, English Language Assessment, Educational Psychology, Journal of Intercultural Communication Research, Journal of Pragmatics, and ReCALL). He co-authored a chapter on Assessing SL Pragmatics in The Cambridge Guide to Second Language Assessment. His research interests include: Sociocultural Theory and SLA, Interlanguage and Intercultural Pragmatics, Language Testing and Assessment, and Teacher Education.

Marzieh Poorzangeneh received her M.A in TEFL from Shahrekord University. She has been teaching English in several language institutes in Isfahan. Her main research interests include psycholinguistic, sociolinguistic, and CALL.

\section{References}

Akbari, R., \& Hosseini, K. (2007). Multiple intelligences and language learning strategies: Investigating possible relations. System, 36, 41-155.

Al-Balhan, E. M. (2006). Multiple intelligence styles in relation to improved performance in Kuwaiti middle school reading. Digest of Middle East Studies, 15(1), 18-34.

Anderson, N. J. (2007). Active skills for reading, book 3 ( $2^{\text {nd }}$ Ed.). Boston: Thomson ELT.

Arbuckle, L. J. (2007). AMOS ${ }^{\mathrm{TM}} 16.0$ user's guide. PA, USA: Amos Development Corporation.

Armstrong, T. (2003). Multiple intelligences of reading and writing: Making the words come alive. Alexandria, VA: ASCD Publications.

Armstrong, T. (2004). Making the words roar, reading strategies aimed at multiple intelligences can make literacy come to life for all students. Educational Leadership, 61(6), 78-81. 
Armstrong, T. (2009). Multiple Intelligence in the classroom $\left(3^{\text {rd }}\right.$ Ed.). Virginia: ASCD Publications.

Barnet, S., \& Bedau, H. (2010). Critical thinking, reading, and writing: A brief guide to argument $\left(7^{\text {th }}\right.$ Ed.). New York: Bradford/St. Martin's.

Çelik, S. (2012). The influence of multiple intelligences on teaching reading in a foreign language. Journal of Education, 1(1), 5-9.

Chen, S. (2005). Cooperative learning, multiple intelligences and proficiency: Application in college English language teaching and learning. Unpublished doctoral dissertation, Australian Catholic University, Australia.

Cho, Y. (2012). Teaching summary writing through direct instruction to improve text comprehension for students in ESL/EFL classroom.Unpublished master's thesis, University of Wisconsin-River Falls, WI, USA.

Christison, M. A. (1996). Teaching and learning languages through multiple intelligences. TESOL Journal, 6(1), 10-14.

De Bono, E. (1995). Mind power. New York: Dorling Kindersley.

Ennis, R. H. (2003). Critical thinking assessment. In D. Fasko (Ed.), Critical thinking and reasoning (pp. 293-310). Cresskill, NJ: Hampton Press.

Facione, P. A. (2011). Think critically. Englewood Cliffs, NJ: Pearson Education.

Farjami, H. (2002). The applications of MI theory in designing activities and for teaching English. (Unpublished master's thesis). University of Semnan, Semnan, Iran.

Foong, L. M., Shariffudin, R. S., \& Milsan, N. (2102). Pattern and relationship between multiple intelligences, personality traits, and critical thinking skills among high achievers in Malaysia. International Proceedings of Economics Development \& Research, 27, 205-209.

Gelder, T. (2007). Teaching critical thinking, some lessons from cognitive science. College Teaching, 53(1), 41-46.

Gaines, D., \& Lehmann, D. (2002). Improving student performance in reading comprehension through the use of multiple intelligences. (Unpublished master's thesis). Saint Xavier University, Chicago, USA. 
Gardner, H. (1983). Frames of mind: The theory of multiple intelligences. New York: Basic Books.

Gardner, H. (1999). Intelligence reframed. New York: Basic Books.

Ghanizadeh, A., \& Moafian, F. (2011). Critical thinking and emotional intelligences: Investigating the relationship among EFL learners and the contribution of age and gender. Iranian Journal of Applied Linguistics (IJAL), 14(1), 23-48.

Haley, M. H. (2001). Understanding learner-centered instruction from the perspective of multiple intelligences. Foreign Language Annals, 34(4), 355-367.

Haley, M. H. (2004). Learner-centered instruction and the theory of multiple intelligences with second language learners. Teachers College Record, 106(1), 163-180.

Hawkins, T. K. (2012). Thinking and reading among college undergraduates: An examination of the relationship between critical thinking skills and voluntary reading. (Unpublished doctoral dissertation). University of Tennessee, Knoxville, USA.

Hoerr, T. R., Boggeman, S., \& Wallach, C. (2010). Celebrating every learner: Activities and strategies for creating a multiple intelligences classroom. San Francisco: Jossey-Bass.

Hoyt, L. R. (2010). The effect of self-regulatory strategy development on reading comprehension ability for students with emotional and behavioral disability. (Unpublished doctoral dissertation).University of Washington, Washington, USA.

Jain, M. (2001). Excellence in government. Delhi: Atlantic Publishers.

Li, M., \& Kirby, J. R. (2014). Unexpected poor comprehends among adolescent ESL students. Scientific Studies of Reading, 18(2), 75-93.

Kim, S. (2001). Characteristics of EFL readers' summary writing: A study with Korean university students. Foreign Language Annals, 34(6), 569-581.

Kirkland, M. R., \& Saunders, M. P. (1991). Maximizing student performance in summary writing: Managing cognitive load. TESOL Quarterly, 25(1), 105121. 
Kissner. E. (2006). Summarizing, paraphrasing, and retelling skills for better reading, writing, and test taking. Heinneman: Portsmouth.

Kobayashi, K. (2007). The influence of critical reading orientation on external strategy use during expository text reading. Educational Psychology, 27(3), 363-375.

Larson-Hall, J. (2010). A guide to doing statistics in second language research using SPSS. New York: Routledge.

McMahon, S. D., Rose, D. E., \& Parks, M. (2004). Multiple intelligences and reading achievement: An examination of the Teele inventory of multiple intelligences. The Journal of Experimental Education, 73(1), 41-52.

Mehta, S. R., \& Al-Mahrooqi, R. (2015). Can thinking be taught? Linking critical thinking and writing in an EFL context. RELC Journal, 46(1), 23-36.

Mohammadyari, A. (2002). The relationship between critical thinking and change management of the heads of the educational departments in Ferdowsi University of Mashhad. (Unpublished master's thesis). Ferdowsi University, Mashhad, Iran.

Mohd Zin, Z., \& Bee Eng, W. (2014). Relationship between critical thinking dispositions and critical reading skills of Malaysian EFL learners. The Asian EFL Journal, 16(4), 41-68.

Mohd Zin, Z., Bee Eng, W., \& Rafik-Galea, S. (2014). Critical reading ability and its relation to L2 proficiency of Malaysian ESL learners. 3L: The Southeast Asian Journal of English Language Studies, 20(2), 43-54.

Moon, J. (2008). Critical thinking: An exploration of theory and practice. London: Routledge.

Neufeld, P. (2005). Comprehension instruction in content area classes. Intentional Reading Association, 59(4), 302-312.

Paul, R., \& Elder, L. (2006). Critical thinking: Tools for taking charge of your leaning and your life ( $\left.2^{\text {nd }} E d.\right)$. NJ: Prentice Hall.

Richards, C. J., \& Bohlke, D. (2012). Four corners 3. Cambridge: Cambridge University Press. 
Rinehart, S. D., Stahl, S. A., \& Erickson L. G. (1986). Some effects of summarization training on reading and studying. Reading Research Quarterly, 21(4), 22-38.

Schreiber, J., Stage, F., King, J., Nora, A., \& Barlow, E. (2006). Reporting structural equation modeling and confirmatory factor analysis results: A review. The Journal of Educational Research, 99(6), 323-337.

Simpson M. (2000). Practicing multiple intelligences in an EFL class. TESOL Journal, 9(1), 30-32.

Sukeemok, T. (2012). Effect of using multiple intelligence theory based activities on English reading comprehension and students' interest in learning English of Matthayomsuksa III students at Taweethapisek School. (Unpublished master's thesis). Srinakharinwirot University, Bangkok, Thailand.

Tahriri, A., \& Yamini, M. (2010). On teaching to diversity: Investigating the effectiveness of MI-Inspired instruction in an EFL context. The Journal of Teaching Language Skills (JTLS), 2(1), 165-183.

Waters A. (2006). Thinking and language learning. ELT Journal, 60(4), 237-319.

Watson, G. B., \& Glaser, E. M. (1980). WGCTA Watson-Glaser critical thinking appraisal manual: Forms $A$ and B. San Antonio: The Psychological Corporation.

Yu, G. (2008). Reading to summarize in English and Chinese: A tale of two languages? Language Testing, 25(4), 521-551.

Yumin, W., \& Henderson, F. (2014). Teaching content through moodle to facilitate students' critical thinking in academic reading. The Asian EFL Journal, 16(3), 7-40.

\section{Appendix A}

Sample of the items in the RC test

Instruction: You will read four passages. Each one is followed by several questions about it. For multiple-choice questions, you are to choose the one best answer, (a), (b), (c), or (d), to each question. Then, on your answer sheet, find the 
number of the question and fill in the space that corresponds to the letter of the answer you have chosen. For true/false questions, you are to choose either T (if the statement is true) or F (it is false). Then, on your answer sheet, find the number of the question and fill in the space that corresponds to the letter ( $\mathrm{T}$ or F).

\section{Passage 1:}

Bananas are widely believed to grow on trees: this is incorrect. The banana is a plant which finishes all its growth in one year, reaching a height of 30 feet. Bananas have an underground stem from which come large, green leaves. The plant reaches its maturity in about 18 months.

As the bunches of bananas mature and the fruit develops, they can be stayed up with poles and covered with blue polyethylene legs. These prevent bruising, protect against frost, and speed ripening by increasing heat and humidity. Once the banana plant has produced its fruit, the mother plant dies and is replaced by pups (sucker plants). These grow next to the parent and make a new generation of banana plants.

\section{Multiple-Choice Questions (Sample Items)}

1. The next sentence after the passage is most likely to be:

a) The old banana plants are chopped up and used as manure.

b) Chicken manure can now be used to feed all kinds of banana plants.

c) Bananas are used in dessert recipes all over the world.

d) Bananas are grown all over south and central America.

2. What does "this" in line 1 refer to?

a) The belief that bananas grow on trees.

b) Certain beliefs about bananas.

c) Widely-held beliefs about banana trees.

d) The belief that bananas do not grow on trees.

3. What would be the best title for the first paragraph?

a) Beliefs about banana plants. 
b) The growth of banana plant to maturity.

c) A year in the life of banana plant.

d) Banana plants: from birth to maturity.

4. What is the main idea of the last paragraph?

a) How the banana plant produce its fruit.

b) How a sucker plant is called a pup.

c) The death of mother plants.

d) The growth of sucker plants.

5. Another way of expressing the last sentence is:

a) Sucker plants grow beside the parent plant and create new banana plants.

b) A new generation of parent plants grows next to the sucker plants.

c) Growing next to the parent plants helps sucker plants make a new generation of banana plant.

d) Parent plants have sucker plants growing beside them; two generations of plants thus grow together.

\section{True/False questions (Sample Items)}

6. The text is mainly scientific

$\mathrm{F}$

7. Many people know that the banana dose not grow on tree

$\mathrm{F}$

\section{Appendix B}

\section{I: A sample of text for summary}

The manatees are giant marine mammals that live in the oceans and rivers around Florida. Usually, adults are about 10 feet long and have a weigh close to 
1,000 pounds. They are often called as sea cows. They eat weeds in the rivers just like cows that eat grass.

Forty years ago, only 1,900 manatees were alive. Thus, manatees were put on the endangered-species list. Though there are more manatees alive today, manatees are still in danger from hunters and I strongly believe that manatees need protection.

One reason for saving them is that the manatees are an important part of our eco-system. For example, they eat weeds and plants and keep rivers clean. A manatee which has 1,000-pound eats 150 pounds of river-clogging weeds in just one day; they help to keep rivers clean for boaters and fishermen.

The next reason is that, manatees are a great tourist attraction. They are fun to watch. For example, every year 70,000 people visit Crystal River in Florida to see and swim with manatees. The tourists help the local business as well.

At last, manatees are beautiful and peaceful creatures so they are worth saving. Recently, the Florid Fish and Wildlife Conservation Commission voted to take the manatee off the state's endangered-species list. They claim that 3,100 manatees are now living in Florida's waters. Therefore, they say that the manatees are not an endangered species.

But the manatees are still in danger and need protection. In 2006, 416 manatees died. More than $65 \%$ of all manatee deaths were caused by people. Because manatees float just under the surface of water, boats often run into them and kill them. Some manatees were shot by the hunters. Others died from swallowing fishhooks and old fishing lines. Swimmers who hang onto their fins often hurt manatees too.

Humans are responsible for most death of manatees. Thus, we must do something to save the manatees. Manatees should stay on the endangered species list, which makes it illegal to shoot them or hurt them. People can help save the manatees by obeying boating speed limits and slowing down in manatees areas. So let us join to save manatees. 
II: A sample of summarization scoring rubric

\begin{tabular}{|c|c|}
\hline Student & Number: ... \\
\hline & Score 0,1 , or 2 \\
\hline & $2=$ fully supported idea \\
\hline & $1=$ idea is mentioned but not fully supported \\
\hline & $0=$ idea not present in summary \\
\hline & $\begin{array}{l}\text { The manatees are giant marine mammals that live in the oceans and rivers around } \\
\text { Florida. }\end{array}$ \\
\hline 2. & Manatees were put on the endangered-species list. \\
\hline 3. & Manatees need protection. \\
\hline 4. & Manatees are an important part of our eco-system. \\
\hline 5. & Manatees are a great tourist attraction. \\
\hline 6. & $\begin{array}{l}\text { Florid Fish and Wildlife Conservation Commission voted to take the manatee off } \\
\text { the state's endangered-species list. }\end{array}$ \\
\hline 7. & More than $65 \%$ of all manatee deaths were caused by people. \\
\hline 8. & Boats often run into them and kill them. \\
\hline 9. & Humans are responsible for most death of manatees. \\
\hline & $\begin{array}{l}\text { People can help save the manatees by obeying boating speed limits and slowing } \\
\text { down in manatees areas. }\end{array}$ \\
\hline Total sc & ore: ... \\
\hline
\end{tabular}




\section{Appendix C}

I: Output data from SEM

\section{Table B1}

Goodness of Fit Indicators in SEM

\begin{tabular}{cccccccc}
\hline $\begin{array}{c}\text { RMSEA } \\
\text { Probability } \\
\text { Level }\end{array}$ & RMSEA & $\begin{array}{c}\text { Probability } \\
\text { Level }\end{array}$ & $d f$ & $\begin{array}{c}\text { Chi } \\
\text { Square }\end{array}$ & NNFI & CFI & AGFI \\
\hline 0.124 & 0.048 & 0.093 & 44 & 55.93 & 0.90 & 0.91 & 0.90 \\
\hline 0.425 & 0.053 & 0.400 & 20 & 20.9 & 0.91 & 0.92 & 0.83 \\
\hline 0.300 & 0.063 & 0.082 & 27 & 37.77 & 0.93 & 0.92 & 0.90 \\
& & & & & & & \\
\hline 0.121 & 0.051 & 0.127 & 44 & 52.53 & 0.91 & 0.90 & 0.82
\end{tabular}

II: Tables for checking the Assumptions of t test and ANCOVA 


\section{Table C1}

Tests of Normality for Reading and CT Scores

\begin{tabular}{lcccc}
\hline & & \multicolumn{3}{c}{ Kolmogorov-Smirnov } \\
\cline { 3 - 5 } Group & Variable & Statistic & $d f$ & Sig. \\
\hline \multirow{2}{*}{ Experimental } & Reading & .15 & 28 & .060 \\
Control & & .16 & 28 & .060 \\
& Reading & & & \\
\hline Experimental & & & & \\
Control & $\mathrm{CT}$ & .10 & 28 & .200 \\
\hline
\end{tabular}

Table C2

Tests of Equality of Variance for Reading and CT Scores

\begin{tabular}{lccccc}
\hline Test & Variable & $F$ & $d f 1$ & $d f 2$ & Sig. \\
\hline Levene & Reading & .68 & 1 & 54 & .410 \\
Levene & CT & .07 & 1 & 54 & .790 \\
\hline
\end{tabular}


Table C3

Analysis of Covariance on Reading Scores for the Interaction Effect

\begin{tabular}{lccccc}
\hline \multicolumn{1}{c}{ Source } & $\begin{array}{l}\text { Sum of } \\
\text { Squares }\end{array}$ & $d f$ & Mean Square & $F$ & Sig. \\
& 525.07 & 3 & 175.02 & 24.95 & .000 \\
Corrected Model & 47.91 & 1 & 4.91 & 6.83 & .001 \\
Intercept & 389.39 & 1 & 389.39 & 55.51 & .000 \\
Pretest Reading & 5.75 & 1 & 5.75 & 0.82 & .370 \\
Group * Pretest & 364.77 & 52 & 7.01 & & \\
Error & 97585 & 56 & & & \\
Total & & & & & \\
\hline
\end{tabular}

Table C4

Analysis of Covariance on CT Scores for the Interaction Effect

\begin{tabular}{lccccc}
\hline \multicolumn{1}{c}{ Source } & Sum of Squares & $d f$ & Mean Square & $F$ & Sig. \\
\hline Corrected Model & 1195.02 & 3 & 398.34 & 54.96 & .000 \\
Intercept & 72.72 & 1 & 72.72 & 10.03 & .000 \\
Pretest CT & 1163.03 & 1 & 1163.03 & 160.46 & .000 \\
Group * Pretest & .00 & 1 & .003 & .000 & .980 \\
CT & & & & & \\
Error & 376.91 & 52 & 7.25 & & \\
Total & 120252 & 56 & & & \\
\hline
\end{tabular}

